\title{
Primary Lymphoma of the Larynx: A Case Report and Literature Review
}

\author{
Khaled Khamassi', Madiha Mahfoudhi2 ${ }^{*}$, Habib Jaafoura ${ }^{1}$, Khaoula Ouertani ${ }^{1}$, \\ Wafa Kaabachi', Lobna Bougacha', Rim Lahiani' ${ }^{1}$, Mamia Ben Salah ${ }^{1}$ \\ ${ }^{1}$ Department of Otorhinolaryngology-Head and Neck Surgery, Charles Nicolle Hospital, Tunis, Tunisia \\ ${ }^{2}$ Department of Internal Medicine A, Charles Nicolle Hospital, Tunis, Tunisia \\ Email: ${ }^{*}$ madiha mahfoudhi@yahoo.fr
}

Received 15 April 2015; accepted 7 June 2015; published 10 June 2015

Copyright (C) 2015 by authors and Scientific Research Publishing Inc.

This work is licensed under the Creative Commons Attribution International License (CC BY).

http://creativecommons.org/licenses/by/4.0/

(c) (;) Open Access

\begin{abstract}
Background: Primary non-hodgkin lymphoma of the larynx is a rare entity accounting for $1 \%$ of laryngeal tumors. Fewer than 100 cases have been reported in the literature. Case presentation: $A$ 52-year-old man, presented with a two-month history of dysphonia. Nasofibroscopy showed left submucosal bulging of the laryngeal supraglottic floor. Cervical computed tomography showed extensive left supraglottic mass, with partial lysis of the thyroid cartilage. Direct laryngoscopy showed left submucosal bulging of the supraglottic floor. Transmucosal biopsies were performed. Histological study concluded to the presence of a diffuse large-cell B lymphoma. The patient was treated with chemotherapy followed by external radiotherapy. Evolution was favourable. Conclusion: Although primary laryngeal non-hodgkin lymphoma is rare, it should be considered in the differential diagnosis of a mass in the neck region, especially in the supraglottic area. Direct laryngoscopy with biopsy makes the diagnosis. Treatment and prognosis depend on the stage and the grade of the lymphoma.
\end{abstract}

\section{Keywords}

Larynx, Lymphoma, Laryngoscopy, Chemotherapy, Radiotherapy

\section{Introduction}

Primary non-Hodgkin lymphoma (NHL) most frequently arises in the gastrointestinal tract, and the head and neck is the second most frequent region [1]. Most head and neck lymphomas arise within the Waldeyer ring, but extranodal extralymphatic sites still accounted for $25 \%$ of these tumors. Laryngeal localization is rare, accounting for $1 \%$ of laryngeal tumors. Fewer than 100 cases have been reported in the literature. Although $90 \%$ of 
tumors involving the larynx are squamous cell carcinoma, laryngeal lymphoma is an important differential consideration because lymphoma is treated with chemo-radiation instead of surgery. Early symptoms are subtle and nonspecific, and confirmation of the diagnosis is often difficult. Early detection of lymphoma allows improved patient care and may result in decreased dissemination of the disease process.

The aim of this study is to report a rare case of primary laryngeal lymphoma, and, with a review of the literature, to precise clinical and paraclinical features and also therapeutic modalities of this aggressive lesion.

\section{Case Report}

A 52-year-old man, 15-pack-year smoker and nonalcoholic, presented to our outpatient clinic with a two month history of dysphonia, without dyspnea. Physical examination revealed a left paramedical neck swelling measuring $3 \mathrm{~cm}$ of long axis, with healthy skin and no lymphadenopathy. Nasofibroscopy showed left submucosal bulging of the laryngeal supraglottic floor.

Cervical computed tomography showed extensive left supraglottic mass, measuring $37 \times 32 \mathrm{~mm}$, with partial lysis of the thyroid cartilage (Figure 1 \& Figure 2).

A direct laryngoscopy under general anesthesia was performed, showing left submucosal bulging of the supraglottic floor (Figure 3). Transmucosal deep biopsies were performed. Histological examination showed infiltration by large atypical lymphoid cells with irregular nuclear outlines and multiple prominent nucleoli. Numerous mitotic and apoptotic cells were present (Figure 4). On immunohistochemistry, the cells were positive for CD45 and CD20 and negative for CD3 and bcl2 on. Diagnosis of diffuse large-cell B lymphoma of the larynx was retained.

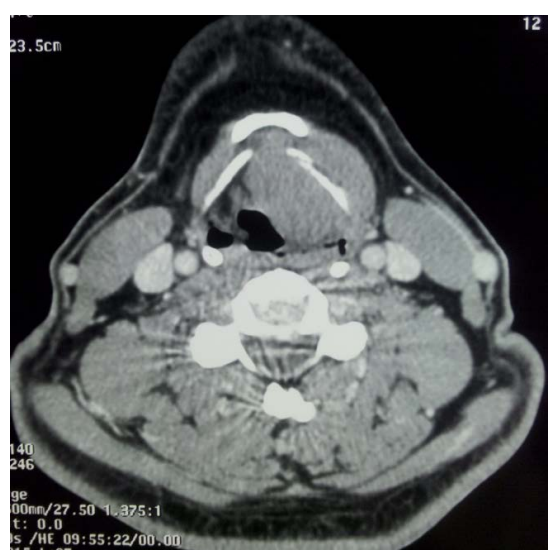

Figure 1. Computed CT (axial): Extensive left supraglottic mass with partial lysis of the thyroid cartilage.

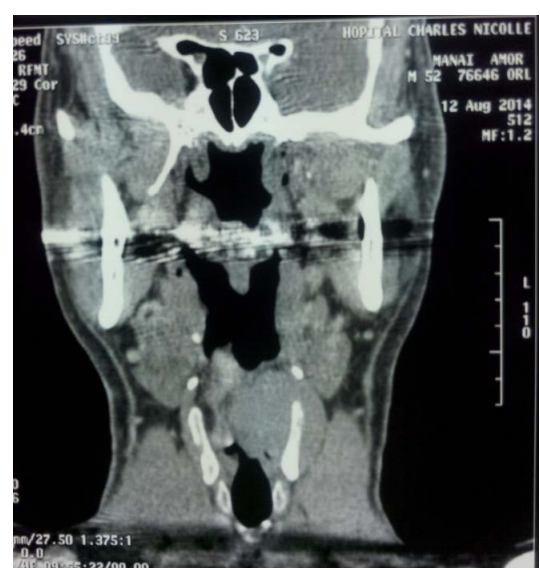

Figure 2. Computed CT (coronal): Extensive left supraglottic mass. 


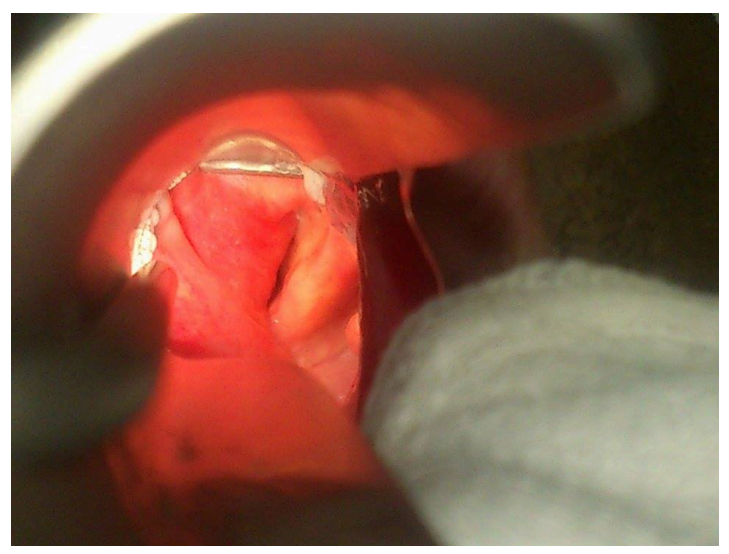

Figure 3. Direct laryngoscopy: Left submucosal bulging of the supraglottic floor.

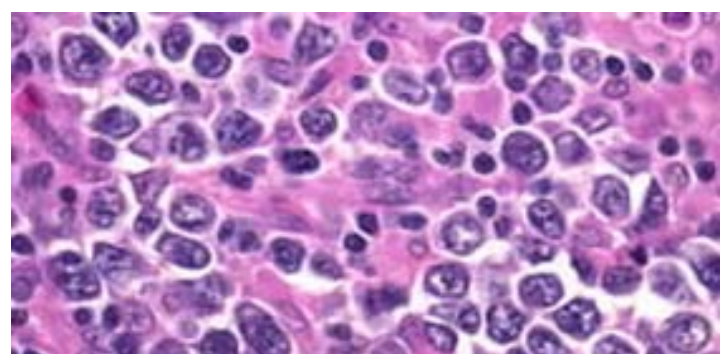

Figure 4. Diffuse large-cell B lymphoma.

Staging with thoraco-abdominal CT and bone marrow biopsy showed no evidence of disease involvement outside of the larynx. Biological investigations showed a normal blood cell count and a normal lactate dehydrogenase level.

These findings were consistent with a diagnosis of diffuse large B-cell (high-grade) NHL of the larynx, with Ann-Arbor stage IE. The patient was treated according to R-CEOP regimen, which is a mixture of rituximab and several chemotherapy drugs. These ones included cyclophosphamide, etoposide, vincristine and prednisone. Three cycles were administrated. Three cycles of this regimen were administrated. The chemotherapy was follow by consolidation external radiation therapy at the dose of $40 \mathrm{~Gy}$ on the neck region. No complications of treatment were noted. Evolution was favourable with no signs of local recurrence. Follow-up period was 3 years.

\section{Discussion}

The most common extranodal head and neck sites of primary non-Hodgkin lymphoma are the paranasal sinuses, the salivary glands, and the thyroid gland [2]. The larynx is a very rare site for these tumors. The low occurrence rate is due to the relatively low lymphoid content in the larynx when compared to other areas in the respiratory tract.

NHL is presumed to arise from 2 locations within the larynx: from aggregates of specialized lymphoid tissue in the submucosa, predominantly of B-cell lineage, or from MALT (Mucosal Associated Lymphoid Tissue) in the aryepiglottic folds and epiglottis [3]. Fewer than 100 cases of lymphoproliferative tumors arising from the larynx (including both NHL and immuno-suppression-related lymphoproliferative diseases) have been previously reported in the literature [4].

The mean age at diagnosis is 70 years, with a range from 4 to 81 years. Sex-ratio has been reported to be variable in different series [5] [6]. Our patient was a 52-year-old male.

Symptoms of NHL are typically site-specific and thus have manifestations similar to those produced by epithelial carcinomas in the same location. These typically include dysphonia, hoarseness, dysphagia, and cervical lymphadenopathy [7]-[9]. Only dysphonia was present in our patient. Systemic symptomatology is unusual, since laryngeal lymphomas tend to remain localized for prolonged periods, though more aggressive forms tend 
to spread earlier [10]. Interestingly, these tumors usually spread to other mucosal sites such as bowel, lung, and orbit rather than nodal sites [7] [8].

In our case, just only a submucosal bulging has suggested the presence of a laryngeal tumor. The literature review shows that all sites inside the larynx can be involved. The commonest anatomical site is the supraglottic region (47\%). Glottic involvement is accounting for $25 \%$ of cases. Paraglottic and subglottic regions are much less commonly affected. Macroscopically, these tumors present as smooth or polypoid masses rather than ulcerated masses [10].

There are certain imaging characteristics that should suggest lymphoma. A large non-necrotic supraglottic lesion with a submucosal component that demonstrates homogeneous enhancement is more characteristic of lymphoma than of squamous cell carcinoma [4]. Laryngeal lymphoma is commonly seen to extend into the laryngeal cartilages, the hypopharynx and the oropharynx. In our patient, partial lysis of the thyroid cartilage was found. Calcifications are not seen with laryngeal lymphoma. Cervical lymphadenopathy, a common finding in supraglottic squamous cell carcinoma, is seen in a smaller percentage of patients with laryngeal lymphoma.

In fact, both macroscopic and radiological appearances of a large laryngeal tumour with a supraglottic submucosal component should alert to the possibility of laryngeal lymphoma [5] [6].

Histologically, primary laryngeal lymphoma is more commonly of B-cell origin, though some T-cell and NKcell lymphomas may be found. The latter are more difficult to diagnose and usually require deep and sometimes repeated biopsy. The unique feature of lymphomas is the fact that these are considered as clonal proliferation of lymphocytes arrested at different stages of differentiation. Immunohistochemistry with various antibodies identifies the specific lineage and the developmental stage. A panel of markers is used, which includes leukocyte common antigen (LCA), B-cell markers (CD20 and CD79a), T-cell markers (CD3 and CD5) and other markers like CD23, bcl-2 and CD10.

It is imperative to stage the lymphomatous process correctly, since treatment varies depending on both the grade and the stage of the disease. PET-CT, in particular, is finding an important place for radiological staging in laryngeal lymphoma, both for low-grade and high-grade ones [11].

The main modalities of treatment were radiotherapy alone or in combination with chemotherapy [12]-[15]. For our patient we opted for 3 cycles of R-CEOP followed by external radiotherapy. Surgical intervention, based on tracheotomy or on laser debulking, is only usually required in patients presenting with acute airway obstruction [10] [13] [16]. Combined chemo-radiotherapy, seems to be the preferred modality of treatment, especially for high-grade lymphomas, and provides an excellent outcome [10] [12] [13] [17].

\section{Conclusion}

Although primary laryngeal lymphoma is rare, it should be considered in the differential diagnosis of a mass in the neck region, especially in the supraglottic area. Computed tomography is very important to evaluate the local extension. Direct laryngoscopy with biopsy makes the diagnosis. Treatment and prognosis depend on the stage and the grade of the lymphoma.

\section{Conflict of Interest}

There are no conflicts of interest.

\section{References}

[1] Ezzat, A.A., Ibrahim, E.M., El Weshi, A.N., Khafaga, Y.M., AlJurf, M., Martin, J.M., et al. (2001) Localized Non-Hodgkin's Lymphoma of Waldeyer's Ring: Clinical Features, Management, and Prognosis of 130 Adult Patients. Head Neck, 23, 547-558. http://dx.doi.org/10.1002/hed.1077

[2] Pak, M.V., Woo, J.K.S. and van Hasselt, C.A. (1999) T-Cell Non-Hodgkin's Lymphoma of the Larynx and Hypopharynx. Otolaryngology—Head and Neck Surgery, 121, 335-336. http://dx.doi.org/10.1016/S0194-5998(99)70203-2

[3] Zapparoli, M., Trolese, A.R., Remo, A., Sina, S., Bonetti, A. and Micheletto, C. (2014) Subglotic Malt-Lymphoma of the Larynx: An Unusual Presentation of Chronic Cough. International Journal of Immunopathology and Pharmacology, 27, 461-465.

[4] King, A.D., Yuen, E.H., Lei, K.I., Ahuja, A.T. and Van Hasselt, A. (2004) Non-Hodgkin Lymphoma of the Larynx: CT and MR Imaging Findings. AJNR American Journal of Neuroradiology, 25, 12-15.

[5] Ansell, S.M., Habermann, T.M., Hoyer, J.D., Strickler, J.G., Chen, M.G. and McDonald, T.J. (1997) Primary 
Laryngeal Lymphoma. The Laryngoscope, 107, 1502-1506. http://dx.doi.org/10.1097/00005537-199711000-00014

[6] Azzopardi, C.P., Degaetano, J., Betts, A., Farrugia, E., Magri, C., Refalo, N., et al. (2014) Laryngeal Lymphoma: The High and Low Grades of Rare Lymphoma Involvement Sites. Case Reports in Medicine, 2014, Article ID: 284643. http://dx.doi.org/10.1155/2014/284643

[7] Yilmaz, M., Ibrahimov, M., Mamanov, M., Rasidov, R. and Oktem, F. (2012) Primary Marginal Zone B-Cell Lymphoma of the Larynx. Journal of Craniofacial Surgery, 23, e1-e2. http://dx.doi.org/10.1097/SCS.0b013e318242055a

[8] Salazar Guilarte, J.X., Sancho Mestre, M. and Gras Albert, J.R. (2012) Laryngeal Manifestation of B-Cell Non-Hodgkin Lymphoma. Acta Otorrinolaringológica Española, 63, 485-487. http://dx.doi.org/10.1016/j.otorri.2011.04.007

[9] Desai, S.C., Allen, C., Chernock, R. and Haughey, B. (2011) Pathology Quiz Case 1. Primary Diffuse Large B-Cell Lymphoma of the Larynx. Archives of Otolaryngology_Head \& Neck surgery, 137, 526,528.

[10] Markou, K., Goudakos, J., Constantinidis, J., Kostopoulos, I., Vital, V. and Nikolaou, A. (2010) Primary Laryngeal Lymphoma: Report of 3 Cases and Review of the Literature. Head \& Neck, 32, 541-549.

[11] Zhao, K., Luo, Y.Z., Zhou, S.H., Dai, B.L., Luo, X.M., Yan, S.X., et al. (2012) 18F-Fluorodeoxyglucose Positron Emission Tomography/Computed Tomography Findings in Mucosa-Associated Lymphoid Tissue Lymphoma of the Larynx: A Case Report and Literature Review. The Journal of International Medical Research, 40, 1192-1206. http://dx.doi.org/10.1177/147323001204000340

[12] Stephenson, K., Peer, S., Govender, D. and Fagan, J.J. (2013) Plasmablastic Lymphoma of the Larynx: Report of Two Cases. The Journal of Laryngology \& Otology, 127, 96-99. http://dx.doi.org/10.1017/S0022215112002149

[13] Elmazghi, A., Elkacemi, H., Lalya, I., Zaidi, H., Harmouch, A., Kanouni, L., et al. (2011) Primary Malignant NonHodgkin Lymphoma of the Larynx: Report of a Case. Pan African Medical Journal, 9, 17. http://dx.doi.org/10.4314/pamj.v9i1.71192

[14] Roca, B., Vidal-Tegedor, B. and Moya, M. (2005) Primary Non-Hodgkin Lymphoma of the Larynx. Southern Medical Journal, 98, 388-389. http://dx.doi.org/10.1097/01.SMJ.0000129938.97092.5F

[15] Word, R., Urquhart, A.C. and Ejercito, V.S. (2006) Primary Laryngeal Lymphoma: Case Report. Ear Nose \& Throat Journal, 85, 109-111.

[16] Paleri, V., Stafford, F.W. and Sammut, M.S. (2005) Laser Debulking in Malignant Upper Airway Obstruction. Head \& Neck, 27, 296-301. http://dx.doi.org/10.1002/hed.20153

[17] Cavalot, A.L., Preti, G., Vione, N., Nazionale, G., Palonta, F. and Fadda, G.L. (2001) Isolated Primary Non-Hodgkin’s Malignant Lymphoma of the Larynx. The Journal of Laryngology \& Otology, 115, 324-326. http://dx.doi.org/10.1258/0022215011907325 